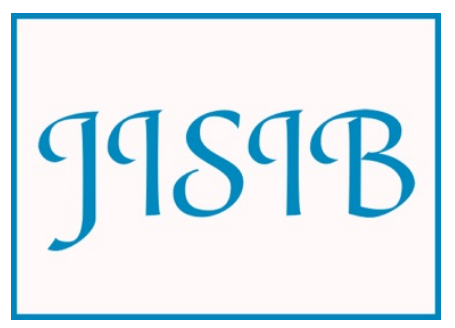

Available for free online at https://ojs.hh.se/

Journal of Intelligence Studies in Business 2 (2013) 40-54

\title{
DEVELOPMENTS IN BUSINESS INTELLIGENCE SOFTWARE ${ }^{1}$
}

\author{
Zhanna Abzaltynova \\ Janice Williams
}

\author{
Blekinge Institute of Technology, Sweden \\ E-mail: zhanna.abzaltynova@gmail.com, jawil79@yahoo.com
}

Received November 10 2012, accepted 6 May 2013

\begin{abstract}
In today's economy the requirements in Business Intelligence environments are changing dramatically. This research paper tested underlying constructs. Hypothesis one sought to test if vendors seek to provide complete BI solutions following all four stages of the CI cycle. The evaluation of BI vendors indicates that all vendors examined do not support planning \& directing phase, except for Astragy that gives users consultations to plan and arrange their $\mathrm{CI}$, its absence did not influence the overall performance score. The second hypothesis sought to test if BI vendors fail to provide good enough solutions for the analysis part of the intelligence cycle. The research findings indicate that only two BI vendors, SAS and QlikView, delivering the analysis phase of the intelligence cycle in a proper way. The third hypothetical construct concerns BI vendors' attempts at making considerable changes in software each year, with each new upgrade. By tracing and comparing the developments of the vendors selected it has been concluded that all BI vendors, irrespective of whether it is a leading traditional vendor or small innovative BI, follow the same tendency in introducing BI enhancements by striving to make its software cost-effective, simpler, faster and flexible for use, scalable to manage increasing amounts of data in businesses, accessible to employees at all levels of organization. Hypothesis four sought to find out if the BI vendors' software tested can be divided into a number of meaningful subgroups. With reference to evaluation and analysis and empirical findings, it has been concluded that the BI vendors can be divided into sub groups and hence has been classified based on their support of the phases of the intelligence cycle, their developments and market information. The
\end{abstract}

\footnotetext{
${ }^{1}$ This paper is an adaptation from a master thesis under the same title completed at BTH in 2010.
} 
subgroups range from advanced, competent, partially competent, and inadequate to absolutely inadequate. Among the BI vendors assessed, none satisfied the criteria in the advanced category. Hypothesis five aspired to determine if the BI software evaluated should fall under a different term as some of them do not follow the entire BI cycle. The analysis of empirical findings identified that QlikView and TIBCO Spotfire deliver the so-called next generation in-memory analytics, which is faster, much simpler, more flexible and scalable and meet the present-day business needs to a far greater extent if compared to traditional BI.

KEYWORDS: Business intelligence, competitive intelligence, business intelligence software, data management, development, business analytics software, SSAV model.

\section{Introduction}

BI has become of much interest to many organizations in the fast changing business environment of today. In Business Week it is highlighted that the recession is fostering interest in BI software, which helps companies analyze the data they collect for new cost-cutting or sales opportunities (Rachel King, 2009). With the present dynamism in the business environment business managers are looking for answers to their questions, and they need these answers much more quickly than in the past. To this end BI software plays an integral role in his process. With all this, there is an increasing demand for a faster turnaround on information requests which places more pressure on the information technology (IT) organizations/BI software vendors who will now have to take on a more flexible and organized approach to providing for BI software users and to establish competitive advantage.

Business intelligence for competitive advantage has become one of the prime prerequisites for competitive advantage in the market place. It is the domain responsible for gathering that information and making it available to decision-makers. For improved decision making, and to enable a competitive advantage, the need for more current information continues to grow.

Most companies are putting out the effort to satisfy this need, but their progress and capabilities vary widely (IBM Redbook, 2004). This research will therefore highlight the developments made by various vendors and the ones who seem to have established a good competitive advantage. In addition to this, the goal is to produce and deliver products quickly and at the lowest cost possible, and to maintain good client satisfaction among BI software users.

\section{Problem Formulation}

Business Intelligence plays an integral role in the decision making process of many organizations today. There are an increasing number of organizations who provide software applications that are aimed at helping companies implement BI systems. These vendors provide various packages which do development overtime while others may have few developments much to the disadvantage of the users.

BI vendors must take into consideration technological innovations and evaluate their ability for improving their existing products. At present BI has attracted much attention from information specialists as well as the business community. This increased attention has given rise to a number of software applications provided by the various vendors who seek to capitalize on these companies' need to implement BI systems. Evaluations have been made of software provided by BI vendors however the focal point of this research is to highlight whether or not these vendors have added more value to the traditional database management software applications.

\section{Scope of the paper}

The purpose of this research is to examine the developments that have occurred with Business Intelligence Software in the last decade. The study will determine and analyze Business Intelligence Software available in the market and trace the developments the major business intelligence vendors are producing in order for companies to stay competitive in a rapidly changing business environment. The thesis research questions are outlined in table 1. 
Table 1. Research Questions

\begin{tabular}{lll} 
Q.1 & $\checkmark$ & $\begin{array}{l}\text { What subgroups can the software } \\
\text { evaluated be divided into? }\end{array}$ \\
Q. 2 & $\checkmark$ & $\begin{array}{l}\text { Do the BI vendors provide good } \\
\text { enough solutions for the analysis } \\
\text { part of the intelligence cycle? }\end{array}$ \\
Q. 3 & $\checkmark$ & $\begin{array}{l}\text { Should some vendors of so-called } \\
\text { BI software fall under a different } \\
\text { category based on the components } \\
\text { of the BI cycle? }\end{array}$ \\
& $\checkmark \quad \begin{array}{l}\text { Do BI vendors make considerable } \\
\text { changes in software each year } \\
\text { with each new upgrade? }\end{array}$ \\
\hline
\end{tabular}

\section{Empirical Research}

The empirical research was performed with the view to study, analyse and evaluate BI vendors and their products. Due to the time constraint and limited access to BI information of some vendors, not all BI vendors were covered in the research. The following BI vendors included in the empirical study: Information Builders, MicroStrategy, IBM Cognos, SAS Institute, SAP Business Objects, Microsoft, QlikView, TIBCO Spotfire, Actuate and Astragy.

Having studied a number of evaluation approaches undertaken by various research organizations with inclusion of SSAV model and having taken into account the objectives of the research, the empirical study was devised to: examine general characteristics of BI functions; perform an analysis of BI software in terms of four CI cycle phases (planning \& directing, data collection, analysis and dissemination) for each BI vendor; to trace the developments introduced by each BI vendor in their recent releases \& present general comparison and similarity of where those enhancements are directed at; to perform an analysis of market share, market segments and pricing structure of BI evaluated. And finally, as per research results, the empirical study endeavoured to categorize BI vendors into a number of subgroups.

The empirical study was performed by way of observations and experiments using the free software trials available at the vendors' web-sites as well as white papers, presentations, data sheets, news with the view to gather information on general characteristics of BI functions, recent BI releases and market statistics. Evaluation criteria of the BI software as per CI cycle phases, presented in the SSAV model as the class of process variables, were taken into consideration herein. Each vendor was evaluated as per each criterion of the four CI cycle phases and rated from not applicable (0) to excellent (4) score. An overall score and then an average score for each intelligence cycle phase were calculated to perform an analysis of BI software. However, it is necessary to point out that the SSAV evaluation model included, performed BI software evaluation according to three classes of variables as process variables (I), product variables and process variables (II). Unlike this research, which attempted to include only process variables (II) in the evaluation (examination of how a BI function supports a particular CI cycle activity), together with the study of BI software recent enhancements and analysis of market information.

\section{Participants}

In an effort to find solutions to the research questions previously outlined, the researchers selected from among the top BI software vendors. To achieve the relevant data the software provided by these vendors were measured on the criteria of the CI cycle phases of planning and directing, data collection, analysis and dissemination. The BI vendors operate in countries across the globe and provide products that are popular enough in the BI software market. It was decided to use those among the top vendors in order to give rational representation of the vendors who actually make new developments in their software gradually. The BI vendors have been mentioned in the initial section of this description.

\section{Instrument to Collect Data}

An instrument was designed to collect the empirical data on the software. The evaluation instrument was designed to determine the level at which the BI vendors provide software based on the CI cycle represented in this study. Each phase was allotted a score of one which gives the evaluation instrument a 
score of zero to four. The scale which follows indicates scores which were used to determine the support of each vendor's software for each stage of the intelligence cycle.

Range-Elucidation
$0 . \quad \mathrm{N} / \mathrm{A}$
1. Poor
2. Satisfactory
3. Good
4. Excellent

This scale was developed by the researchers in order to facilitate the use of the quantitative research method effectively. This ensured the collection of statistics for data analysis. The software provided by these BI vendors were assessed and based on the details provided by white papers, demos and information from the sites of these vendors, they were scaled accordingly.

\section{Analysis of BI vendors as per CI cycle}

The table presented below shows a summary of empirical findings that include BI software evaluation as per evaluation criteria reflected in the Appendix with the average scores calculated for each phase of the intelligence cycle, examination of developments introduced by the tested BI vendors and analysis of their market information i.e. market share, customers and pricing strategy.

As per the Table (1) below, BI software evaluation determined that the planning \& directing phase of the intelligence cycle is not supported by any vendor. Though, Astragy consultants advise users to plan and direct as well as arrange their intelligence system. With respect to the data collection phase, BI software vendors tested support this phase in a fair way with the total average score (3.16) for all vendors (Figure 16). SAP Business Objects is assigned the highest score for the data collection phase, followed by Information Builders, IBM Congos and Astragy. Though, Astragy does not provide any BI functions and can be considered more as CI vendor, it was also included and evaluated along with all other vendors. MicroStrategy turned out to have the lowest score for data collection phase and is the last in the list.
The Source for the table below, in the Evaluation Summary. Note: Cells highlighted in Part II of the Table (2) shows the areas where BI enhancements took place (either in data warehousing, analytics or information delivery). Part III - BI Market information - market share for Astragy is not provided by the vendor, therefore is highlighted in grey. Those BI vendors that deliver its BI products to corporate \& SME segments are highlighted in grey, but for MicroStrategy, which provides its BI software to mainly corporate customers (with "C" indication) and QlikView cell is indicated with " $\mathrm{M}$ " sign that means this vendor is a leader in the midmarket segment. Pricing strategy is indicated with " $\mathrm{S}$ " for standard pricing structure that include named-user and CPU-based, "F" - flexible pricing structure that include other pricing choices but for standard ones. 


\begin{tabular}{|c|c|c|c|c|c|c|c|c|c|c|}
\hline & $\begin{array}{l}\text { Information } \\
\text { Builders }\end{array}$ & $\begin{array}{l}\text { IBM } \\
\text { Congos }\end{array}$ & $\begin{array}{l}\text { SAP Business } \\
\text { Objects }\end{array}$ & SAS & Microstrategy & Qlikview & $\begin{array}{l}\text { TIBCO } \\
\text { Spotfire }\end{array}$ & Actuate & $\begin{array}{l}\text { Micro- } \\
\text { soft }\end{array}$ & Astragy \\
\hline \multicolumn{11}{|c|}{ I. Bi Software Evaluation By Ci Cycle Phases (With Indication Of Average Total Scores) } \\
\hline $\begin{array}{l}\text { 1. Planning } \\
\text { \& Directing }\end{array}$ & 0 & 0 & 0 & 0 & 0 & 0 & 0 & 0 & 0 & 0 \\
\hline $\begin{array}{l}\text { 2. Data } \\
\text { Collection }\end{array}$ & 3.75 & 3.62 & 3.81 & 3.5 & 1.5 & 3 & 3 & 2.5 & 3.25 & 3.6 \\
\hline 3. Analysis & 1.75 & 2.25 & 2.75 & 4 & 2.5 & 4 & 3.8 & 1.5 & 3 & 3.5 \\
\hline $\begin{array}{l}\text { 4. Disse- } \\
\text { mination }\end{array}$ & 3.92 & 4 & 4 & 3.6 & 3.94 & 3.5 & 3.1 & 3.4 & 3.8 & 3.4 \\
\hline \multicolumn{11}{|c|}{ Ii. Bi Software Developments } \\
\hline \multicolumn{11}{|l|}{$\begin{array}{l}\text { Data } \\
\text { Warehousing }\end{array}$} \\
\hline \multicolumn{11}{|l|}{$\begin{array}{l}\text { Business } \\
\text { Analytics }\end{array}$} \\
\hline \multicolumn{11}{|l|}{$\begin{array}{l}\text { Information } \\
\text { Delivery }\end{array}$} \\
\hline \multicolumn{11}{|c|}{ Iii. Bi Market Information } \\
\hline $\begin{array}{l}\text { Market Share } \\
\text { As of } 2007\end{array}$ & $6.00 \%$ & $14.00 \%$ & $26.00 \%$ & $\begin{array}{r}14.4 \\
0 \%\end{array}$ & $5.88 \%$ & $1.57 \%$ & $0.59 \%$ & $2.76 \%$ & $10.60 \%$ & \\
\hline $\begin{array}{l}\text { Customer } \\
\text { Segments }\end{array}$ & & & & & $\mathrm{C}$ & M & & & & \\
\hline $\begin{array}{l}\text { Pricing } \\
\text { Strategy }\end{array}$ & S & $\mathrm{F}$ & $\mathrm{F}$ & $\mathrm{F}$ & $\mathrm{F}$ & $\mathrm{F}$ & $\mathrm{F}$ & $\mathrm{S}$ & $\mathrm{F}$ & S \\
\hline
\end{tabular}

\section{Summary of BI Software Evaluation}

Total average score for the data in the table 1 is shown in Figure 1. We see SAS in first place, Infobuilders on second and Astragy on third place.

Figure 1. BI Vendors Rating on Data Collection

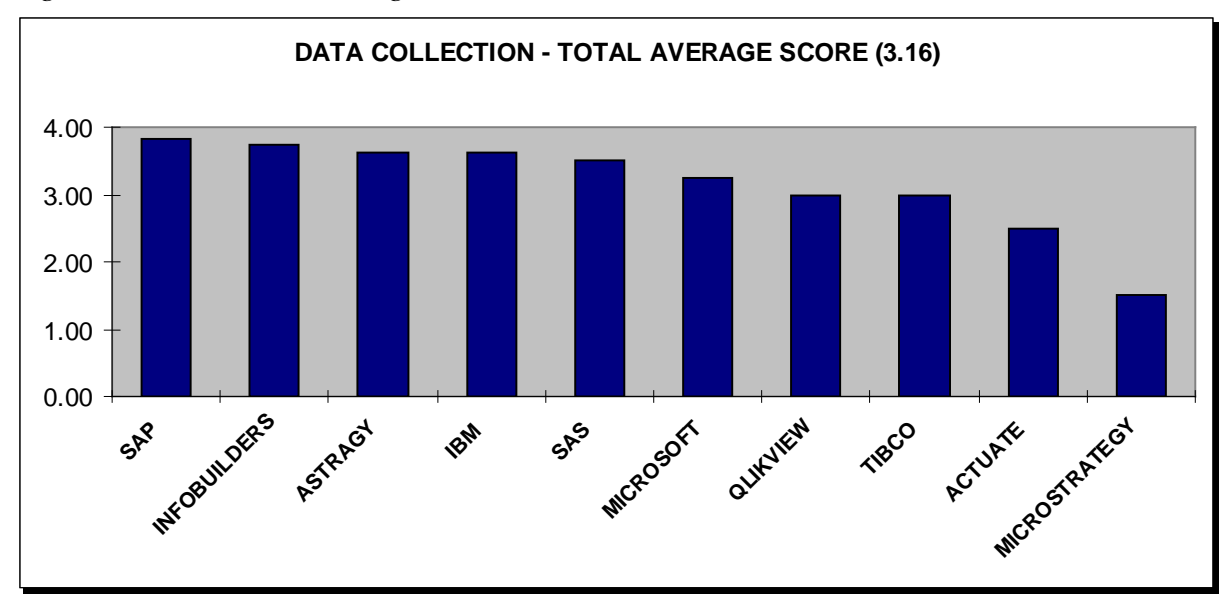


As per the Figure 2 presented below, SAS Institute and QlikView are the best in delivering the analysis phase. Again, Astragy was ranked with other vendors though it does not support any BI functions. Actuate was given the lowest score and support analysis in a poor way. In general, total average score for the analysis phase amounts to (2.9) for all BI software evaluated, which is below the scores for the data collection and dissemination phases. Thus, the evaluation findings prove the thesis hypothesis that BI vendors fail to provide good enough analysis part of the intelligence cycle.

Figure 2. BI Vendors Rating in Analysis

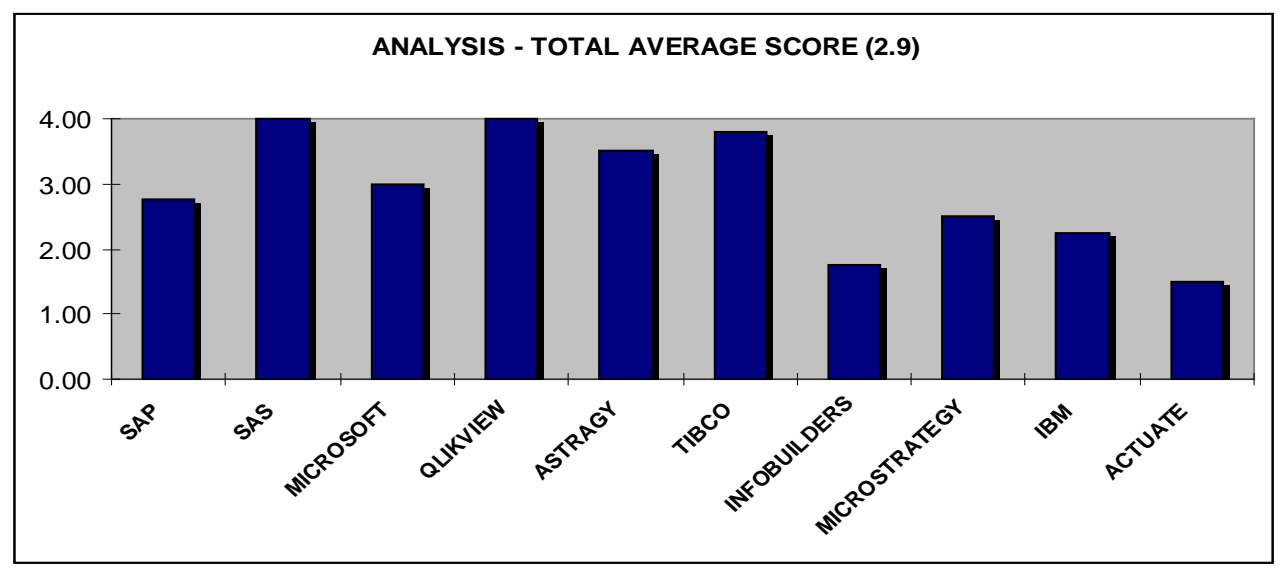

With respect to BI vendors rating in the dissemination phase provided in the Figure 3 below, SAP Business Objects, IBM Cognos, MicroStrategy and Information Builders are the best in dissemination followed by Microsoft, SAS Institute, and QlikView. TIBCO Spotfire has the lowest score for the dissemination phase, therefore is the last among BI vendors. Total average score for the dissemination phase is (3.67) for all BI vendors tested, which is the highest among all CI cycle phases and determines that $\mathrm{BI}$ vendors deliver this phase in a more competent way if compared to other CI cycle phases.

Figure 3. BI Vendors Rating In Dissemination

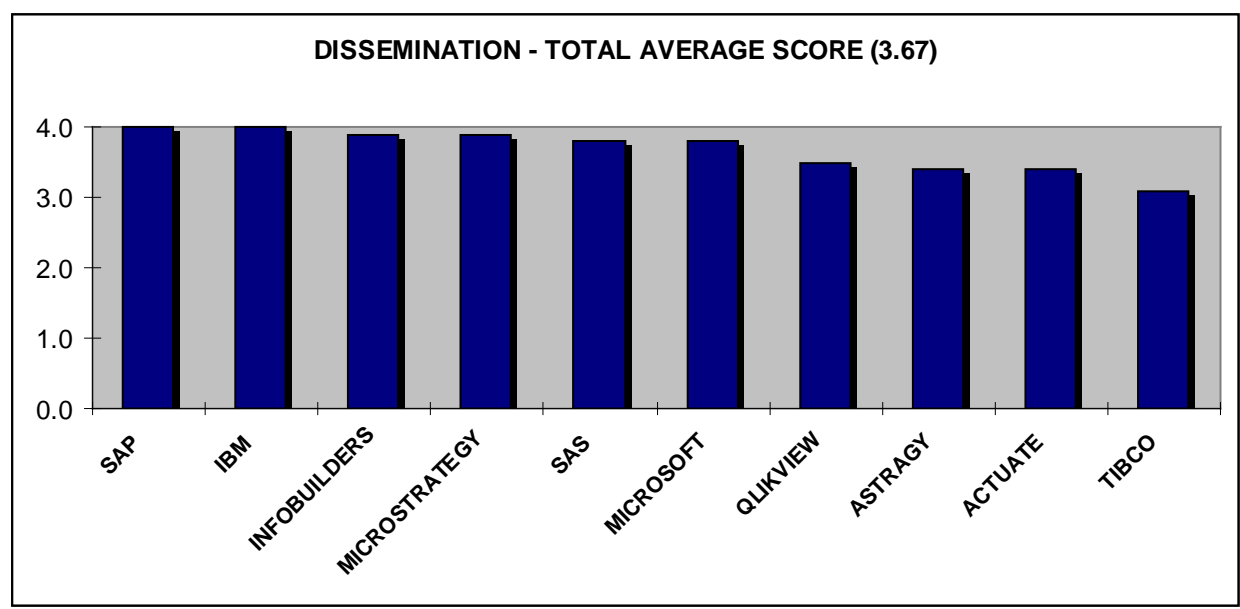


Table 3. Summary Of BI Improvements

\begin{tabular}{|c|c|c|c|}
\hline VENDOR NAME & $\begin{array}{l}\text { PREVIOUS } \\
\text { RELEASE }\end{array}$ & RECENT RELEASE & $\begin{array}{l}\text { IMPROVEMENTS } \\
\text { INTRODUCED IN: }\end{array}$ \\
\hline $\begin{array}{l}\text { 1. Information } \\
\text { Builder }\end{array}$ & WebFOCUS 7 & $\begin{array}{l}\text { WebFOCUS } 7 \text { (with } \\
\text { new features) }\end{array}$ & $\begin{array}{ll}\checkmark & \text { Information Delivery-User } \\
& \text { Interface \& Reporting; } \\
\checkmark & \text { Analytics; }\end{array}$ \\
\hline 2. MicroStrategy & MicroStrategy 8 & MicroStrategy 9 & $\begin{array}{ll}\checkmark & \text { Data Warehousing; } \\
\checkmark & \text { Analytics; } \\
\checkmark & \text { Information Delivery: User } \\
& \text { Interface \& Reporting; }\end{array}$ \\
\hline 3. IBM Cognos & Cognos 8 & $\begin{array}{l}\text { IBM Cognos } 8 \text { version } \\
8.4\end{array}$ & $\begin{array}{ll}\checkmark & \text { Data Integration; } \\
\checkmark & \text { Information Delivery: User } \\
& \text { Interface \& Reporting; } \\
\checkmark & \text { Analytics; }\end{array}$ \\
\hline $\begin{array}{l}\text { 4. SAP Business } \\
\text { Objects }\end{array}$ & $\begin{array}{l}\text { Business Objects } \\
\text { XI } 3.0\end{array}$ & Business Objects XI 3.1 & $\begin{array}{ll}\checkmark & \text { Data Integration; } \\
\checkmark & \text { Information Delivery: User } \\
& \text { Interface \& Reporting; }\end{array}$ \\
\hline 5. SAS Institute & SAS 9.1 & SAS 9.2 & $\begin{array}{ll}\checkmark & \text { Data Integration; } \\
\checkmark & \text { Analytics; } \\
\checkmark & \text { Information Delivery: User } \\
& \text { Interface \& Reporting; }\end{array}$ \\
\hline 6. Microsoft & SQL Server 2005 & SQL Server 2008 & $\begin{array}{ll}\checkmark & \text { Data Warehousing; } \\
\checkmark & \text { Analytics; } \\
\checkmark & \text { Information Delivery: User } \\
& \text { Interface \& Reporting; }\end{array}$ \\
\hline 7. QlikView & QlikView 8 & QlikView 8.5 & $\begin{array}{ll}\checkmark & \text { Analytics; } \\
\checkmark & \text { Data Integration; } \\
\checkmark & \text { Information Delivery; }\end{array}$ \\
\hline 8. TIBCO Spotfire & Spotfire DXP & TIBCO Spotfire 2.2 & $\begin{array}{ll}\checkmark & \text { Analytics; } \\
\checkmark & \text { Information Delivery: User } \\
& \text { Interface \& Reporting; }\end{array}$ \\
\hline 9. Actuate & Actuate 9 & Actuate 10 & $\begin{array}{l}\checkmark \text { Information Delivery: User } \\
\text { Interface \& Reporting; }\end{array}$ \\
\hline 10. Astragy & $\begin{array}{l}\text { Astragy Enterprise } \\
\text { Edition }\end{array}$ & $\begin{array}{l}\text { Astragy Enterprise } \\
\text { Edition (with new } \\
\text { features as add-on } \\
\text { modules on request) }\end{array}$ & $\begin{array}{ll}\checkmark & \text { Analytics; } \\
\checkmark & \text { Data Collection; } \\
\checkmark & \text { Dissemination; }\end{array}$ \\
\hline
\end{tabular}


The Table 3 presented above, provides an overview of BI previous and recent releases introduced by the vendors with indication of areas where these improvements or developments took place either in data warehousing, business analytics or information delivery.

Upon the information provided above, one can come to a conclusion that each vendor endeavours to introduce significant and new enhancements/developments each year either with current release or presenting upgrades within an existing release. The following vendors delivered new BI releases: MicroStrategy, IBM Cognos, SAP Business Objects, SAS Institute, Microsoft, QlikView, TIBCO Spotfire, and Actuate. Information Builders presented its BI software under name WebFOCUS 7 with new enhancements and Astragy introduced new features in its product Astragy Enterprise Edition as add-on modules on request.

MicroStrategy, with its recent release MicroStrategy 9, delivers BI with greater scalability, performance and efficiency as well as merges BI applications cohesively and consistently to all departments and workgroups at the organization. IBM Cognos version 8.4 endeavours to extend BI to a broader range of business users at all levels of organization and provide greater access to information through advanced search Cost-effectiveness to a wide range of business users.

\section{Summary \& Analysis of BI Market Information}

According to the Table 2 Evaluation Summary presents the worldwide market shares of the $\mathrm{BI}$ software of the following vendors: SAP, IBM, Information Builders, MicroStrategy, SAS Institute, Microsoft, QlikView, Actuate, and TIBCO. Astragy market share is not reflected in the figure as the vendor did not wish to reveal the market share of its product. Unfortunately, due to limited access to these data and inability to separate and identify BI revenues from the overall revenues capabilities. SAP Business Objects in Business Objects XI 3.1 empowers users with flexibility to access all information regardless of format, shape \& size and location; deliver BI platform that support heterogeneous environments and offer integration with data sources from a variety of vendors. SAS, through its recent release SAS 9.2., delivers a wide range of benefits for both business users and IT departments, for instance, by improving and simplifying advanced analytics to all decision makers. Microsoft, with its SQL Server 2008, provides businesses with high levels of security, reliability and scalability, enables to reduce time and cost to develop and manage their data infrastructure as well as delivers a comprehensive platform.

Information Builders significantly improved reporting and analysis functions to deliver efficiency and simplicity of use to all business users. QlikView 8.5 with its in-memory business analysis endeavours to deliver BI with greater speed, flexibility, ease-of-use and visual interactivity. Actuate 10, with its comprehensive RIA-ready platform strives to provide costeffective BI and reporting applications that reduce costs and ensure efficiency. And finally, TIBCO Spotfire and Astragy also introduced improvements with the aim to deliver more efficiency and simplicity.

of some vendors as IBM, Microsoft and TIBCO, the BI vendors' market shares for 2008 were not presented herein. Market share of the following BI software: Information Builders, MicroStrategy, QlikView, Actuate and TIBCO for 2007 was derived with BI software market revenue as of 2007 (5, 1 billion USD) and the vendors company revenues. Therefore, the market share of the aforementioned vendors is approximate and rough. More clear graphical presentation of BI software market shares presented in the Figure (4). 
Figure 4. BI Software Market Shares as of 2007

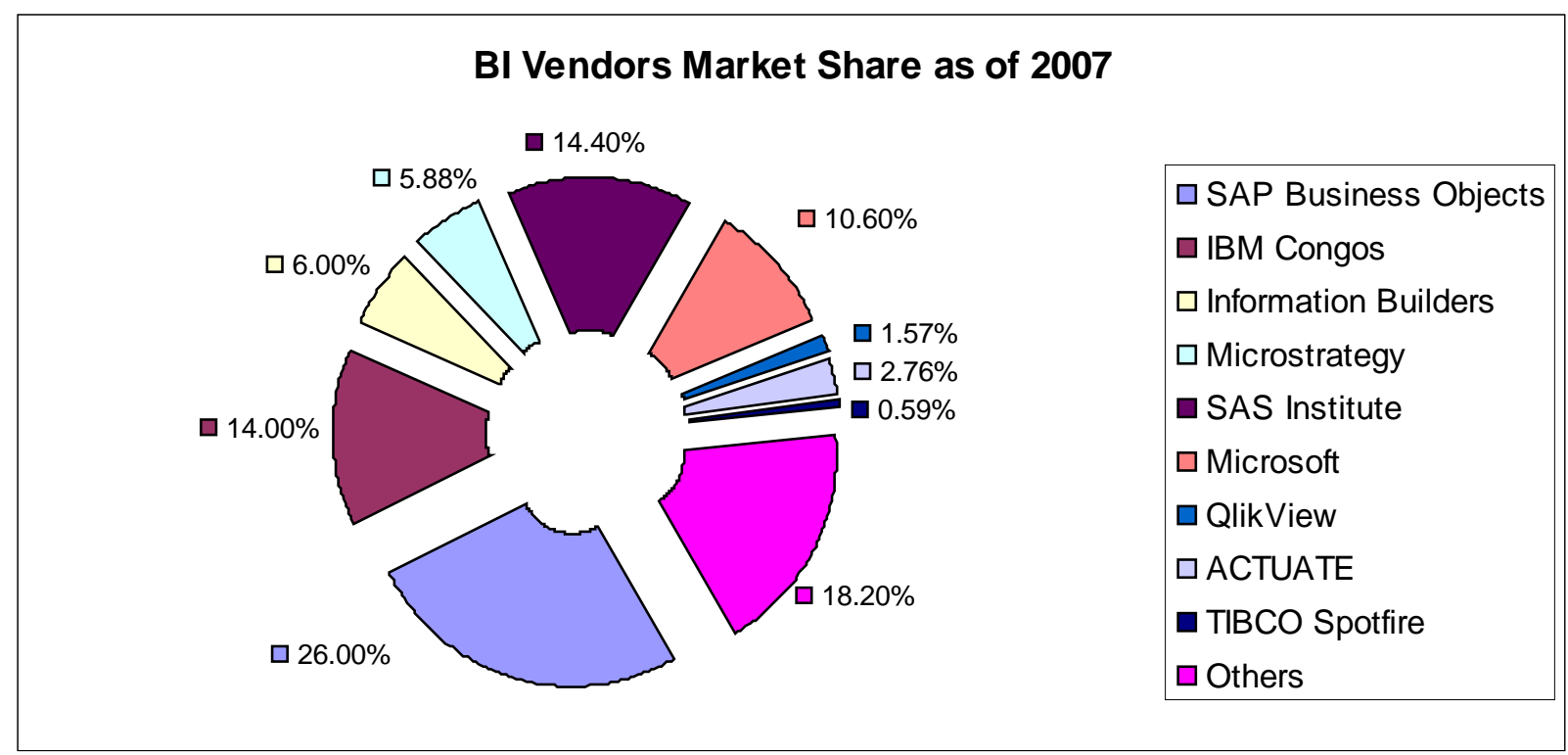

According to the summary of BI software market shares, SAP has the leading market share with $26 \%$ followed by SAS Institute - 14.4\%, IBM - $14 \%$ and Microsoft - $10.6 \%$. The BI vendors having the least market shares are QlikTech and TIBCO. Astragy is listed in the summary table with no indication of its market share as the vendor wished not to disclose its market share. The remaining part of BI market - $18.2 \%$ pertains to the rest BI vendors, not included into the research due to the time constraint.

With respect to customer segments (Table 2), the analysis revealed that almost all vendors deliver its BI software to both enterprise and SME businesses with the exception of MicroStrategy that provides BI to mainly corporate customers and QlikTech is considered a leader in mid-market segment.

As per the Table (2) shows that the majority of BI vendors evaluated provide customers with flexible or multiple license options, these are SAP, IBM, SAS Institute, Microsoft, MicroStrategy and TIBCO. Other vendors as Information Builders, Actuate and Astragy have standard pricing structure based on either named-user or CPU-based or both. Besides, some vendors deliver web-based software and offer SaaS pricing model such as SAP, IBM, MicroStrategy, SAS Institute, Microsoft and QlikView. In addition, some vendors offer distinctive features in their pricing models: SAP delivers user-role-plus-server approach, IBM Cognos `s pricing is role and task-based, Microsoft offers no-charge-for-end-users pricing and
QlikTech `s pricing is cost-efficient as users have to buy what they use.

\section{BI Software Classification}

As per the evaluation and analysis of empirical findings, the BI software can be logically classified into subgroups in terms of its intelligence cycle phases with consideration of their developments and market information. BI vendors, in terms of the support of CI cycle phases, were grouped according to the overall performance of four (4) phases (planning \& directing, data collection, analysis and dissemination). BI software is grouped as follows:

\section{Advanced:}

BI software in this group outperforms in all four CI cycle phases such as planning \& directing, data collection, analysis and dissemination. This BI software has one of the leading market shares, is employed successfully in all market segments, introduce significant developments on annual basis and have the flexible pricing strategy.

2. Competent:

As all BI software evaluated does not support planning \& directing phase, they can be termed "competent" as they support other three CI cycle phases (data collection, analysis and dissemination) in an excellent or almost excellent way. They 
also have the leading market shares, work in all market segments, introduce developments on annual basis and have the flexible pricing strategy together with the standard one.

3. Partially competent:

If BI software perform well at least in two CI cycle phases, it is included in this group. Besides they can work either in all or some of the market segments, have either leading or non-leading market shares, provide enhancements annually and have either flexible or standard pricing structure.

4. Inadequate:

If BI software outperform only in one of four CI cycle phase, they are included in this group. Moreover, they work either in all or some of the market segments, provide enhancements annually and have either flexible or standard pricing structure.

\section{Absolutely inadequate:}

When BI software fails to excel in any of the four CI cycle phases, it is positioned in this group. It can be present either in all or some of the market segments, have significantly small market share, provide developments annually and have either flexible or standard pricing structure.

This classification is applied in the Figure (5) as follows.

Figure 5. BI Software Classification

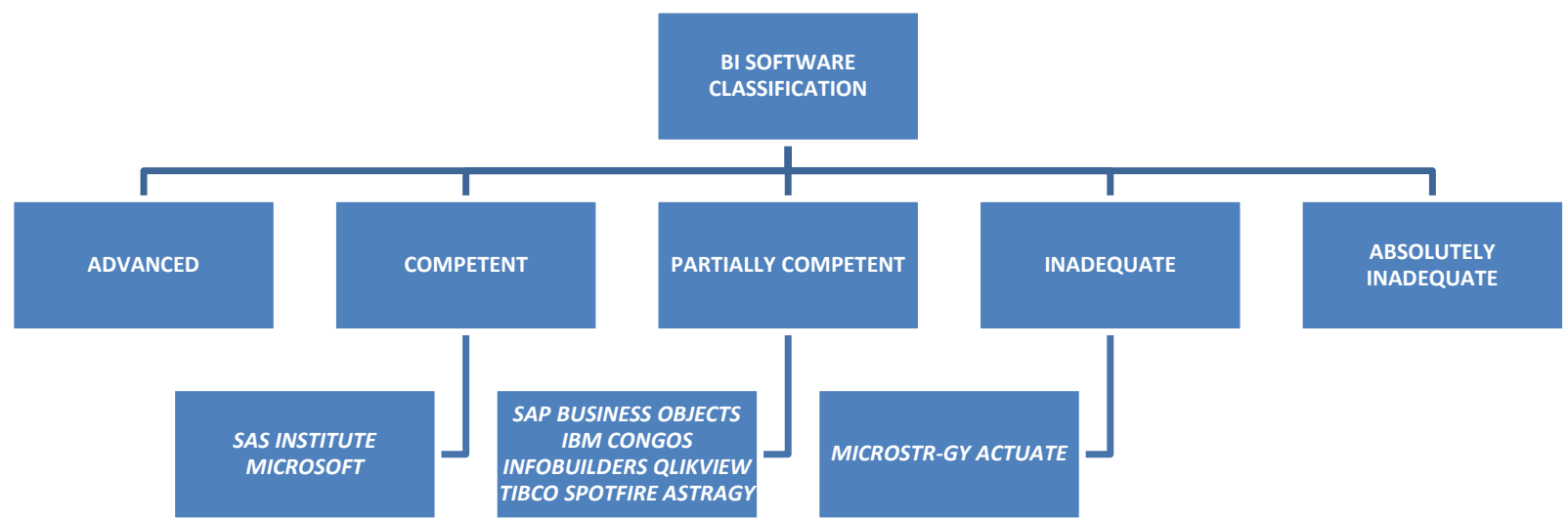

On the basis of the evaluation criteria, SAS Institute and Microsoft are positioned in the group of competent BI software; SAP Business Objects, IBM Congos, Information Builders and QlikView are included in the group of partially competent BI software; and finally, MicroStrategy and Actuate are placed in the group of inadequate BI software. There is not any BI software, at least among the software tested, that could be positioned in the advanced and absolutely inadequate category. QlikView could be placed into the competent group if it had the market share relevant to this category.
In addition to the BI software classification presented above, QlikView and TIBCO Spotfire software can fall under a different term other than BI software as they deliver the so-called next generation in-memory analytics, which is faster, much simpler, more flexible and scalable and meet the present-day business needs to a far greater extent if compared to traditional BI. These software vendors are completely different from traditional BI vendors as they provide greatly enhanced \& efficient analytic capabilities and do not follow the entire BI cycle, and therefore we propose to term them as "Business Analytics Software" instead of 
BI software. Besides, as Astragy does not support any BI functions, it should also be termed differently as CI software, not BI software.

\section{Conclusions \& Recommendations}

Hypothesis one sought to test if vendors seek to provide complete BI solutions following all four stages of the CI cycle. In terms of the support of CI cycle phases; BI vendors were grouped according to the overall performance of four (4) phases (planning \& directing, data collection, analysis and dissemination). The evaluation of BI vendors indicates that all vendors examined do not support planning \& directing phase, except for Astragy that gives users a consultations to plan and arrange their $\mathrm{CI}$, its absence did not influence the overall performance score. Information Builders and SAP Business Objects excel in data collection phase; SAS Institute and QlikView are the best in analysis; SAP Business Objects and IBM Cognos surpass in dissemination phase. It should be noted that Astragy was evaluated along with other vendors though it does not provide any BI functions but only provide common functions for supporting the CI cycle phases.

The second hypothesis sought to test if BI vendors fail to provide good enough solutions for the analysis part of the intelligence cycle. The research findings indicate that only two BI vendors, SAS and QlikView, delivering the analysis phase of the intelligence cycle in a proper way. The overall findings also indicate that BI vendors fail to provide good enough solutions for the analysis part of the intelligence cycle as total average score provided by the evaluation instrument (see Figure 4) among BI vendors for the analysis phase fell below the average scores for the data collection and dissemination phases of the cycle.

The third hypothetical construct concerns BI vendors' attempts at making considerable changes in software each year, with each new upgrade. By tracing and comparing the developments of the vendors selected it has been concluded that all BI vendors, irrespective of whether it is a leading traditional vendor or small innovative BI, follow the same tendency in introducing BI enhancements by striving to make its software cost-effective, simpler, faster and flexible for use, scalable to manage increasing amounts of data in businesses, accessible to employees at all levels of organization. Most of the vendors introduced a support for heterogeneous environments and data sources from a variety of vendors.

Hypothesis four sought to find out if the BI vendors' software tested can be divided into a number of meaningful subgroups. With reference to evaluation and analysis and empirical findings, it has been concluded that the BI vendors can be divided into sub groups and hence has been classified based on their support of the phases of the intelligence cycle, their developments and market information. The subgroups range from advanced, competent, partially competent, and inadequate to absolutely inadequate. Among the BI vendors assessed, none satisfied the criteria in the advanced category.

Hypothesis five aspired to determine if the BI software evaluated should fall under a different term as some of them do not follow the entire BI cycle. The analysis of empirical findings identified that QlikView and TIBCO Spotfire deliver the socalled next generation in-memory analytics, which is faster, much simpler, more flexible and scalable and meet the present-day business needs to a far greater extent if compared to traditional BI. Besides, they do not follow the entire BI cycle and it is suggested herein to term them as Business Analytics Software instead of BI software. Moreover, as Astragy does not support any BI functions, it is also suggested to term it differently as CI software, not BI software.

BI software is among the many software that organizations utilize to ensure their stay in the market. BI enables organizations to make well informed business decisions and thus can be the source of competitive advantages and perform the ultimate objective improving the timeliness and quality of decisions. Developments in BI software eventually play the role of improving the overall performance of the organization using them by enabling the company to respond quickly and adapt to changes. It is within this framework that this research has been directed and is alluded to by the hypotheses above.

Fundamentally, the evaluation of BI software development has gleaned data which shows that BI software vendors have made significant improvements with their product offerings. Developments in information delivery, userinterface, reporting, analytics, and data integration are evident with BI vendors examined for the purpose of this research. BI vendors have also seen developments in their possession of market share 
among these software providers. It has been observed that SAP Business Objects has the leading market share as opposed to other competitors. Majority of these BI vendors also provide multiple licence options in the market. Generally BI vendors do make significant developments with BI software over time and this they have all recognized is necessary to ensure competitive advantage. With regards to the intelligence cycle, one can allude that few are lacking much in data collection and dissemination, very few are supporting analysis duly, but all BI vendors used for the purpose of this research fell short on the planning and direction phase.

Based on the findings it is being suggested, further investigation of all BI software vendors is recommended with an in-depth analysis of CI cycle phases based on the enhanced evaluation criteria as well as newly approached analysis and evaluation of recent BI developments, present market shares and pricing structures is suggested for further studies. A further analysis of BI market share for 2008 should be carried out to reflect the presentday situation.

The research will provide further details concerning the developments that have been made in BI software among a select group of vendors, the extent to which the software provided by these vendors cover the areas which comprise the business intelligence cycle. It will also further highlight the new developments that have taken place with the software compared to previous release by vendors, the market share of the software and the market that exists for these providers.

The objectives of this research were inclined towards analyzing BI software available in the market as well as tracing the developments that have taken place within the sphere of BI software. Specifically, the improvements which have taken place over the past five years, determine the compatibility of BI software to the phases of the intelligence cycle, determine subgroups that BI software vendors may be classified as and assess the changes that these BI vendors have made based on the new upgrades that are announced at intervals.

The empirical and theoretical research has revealed a number of findings as it relates to the developments in BI software. It has been deduced that of the selected BI vendors used for his research, most satisfy all three phases of the cycle, except that of planning and direction. Data collection, analysis and dissemination were applicable to all vendors from a satisfactory basis to excellence in terms of compatibility with the phases. The research has also revealed that BI vendors have made significant improvements in data integration, information delivery, analytics, user interface and reporting. BI vendors are therefore cognizant of the fact that innovation plays an integral role for survival in the BI market. Assessment of the developments in BI software has been propelled by the need to create cost effective products for the various users groups of their software.

As per the analysis of the empirical findings of only (10) BI vendors due to time constraint, we identified that SAP Business Objects followed by Information Builders, IBM Congos and Astragy excel in data collection phase; SAS Institute and QlikView are the best in analysis; SAP Business Objects and IBM Congos surpass in dissemination phase. It should be noted that Astragy was evaluated along with other vendors though it does not provide any BI functions but only provide common functions for supporting the CI cycle phases. Besides, it is made obvious that analysis phase is not supported in a good enough way by BI vendors basing on the total average score for all BI software for analysis (2.9) compared to the total average scores for data collection (3.16) and dissemination (3.67).

Besides, the empirical findings helped to identify that BI vendors introduce their releases with new developments each year. By tracing and comparing the developments of all (10) vendors, we came to a conclusion that all BI vendors, irrespective of whether it is a leading traditional vendor or small innovative $\mathrm{BI}$, follow the same tendency in introducing $\mathrm{BI}$ enhancements by striving to make its software cost-effective, simpler, faster and flexible for use, scalable to manage increasing amounts of data in businesses, accessible to employees at all levels of organization. Moreover, most of the vendors introduced a support for heterogeneous environments and data sources from a variety of vendors.

In addition, the analysis of BI software market share, customers and pricing strategy in the empirical findings revealed that SAP Business Objects had the largest BI market share of $26 \%$ percent as of 2007, followed by SAS Institute, IBM 
Congos and Microsoft. Hence, further analysis of BI market share should be carried out to reflect the present-day situation. The analysis of customers` segments showed that almost all vendors deliver its BI software to enterprises and SME businesses, but for MicroStrategy that work mainly with corporate segment. The investigation of BI software pricing strategy identified that majority of BI vendors employ flexible or multiple choice licensing models along with traditional licensing as nameduser and CPU-basis. Some of BI vendors as SAP Business Objects, IBM, MicroStrategy, SAS and Microsoft also support SaaS pricing model. Yet, more detailed analysis of pricing structure and actual cost ought to be made to create a much clearer picture of BI software market.

Finally, as per the results of the software evaluation, based on the overall scores of CI cycle phases, BI software can be classified into five groups: Advanced, Competent, Partially Competent, Inadequate and Absolutely Inadequate. SAS Institute and Microsoft are positioned in the group of competent BI software; SAP Business Objects, IBM Congos, Information Builders and QlikView are included in the group of partially competent BI software; and finally, MicroStrategy and Actuate are placed in the group of inadequate BI software. The analysis of empirical findings identified that there is not any BI software, at least among the software tested that could be positioned in the advanced and absolutely inadequate category.

Moreover, QlikView and TIBCO Spotfire with its in-memory analytics are suggested to term as Business Analytics Software due to its distinction with traditional BI software and non-adherence to the entire BI cycle. Accordingly, the objectives hereof were fulfilled through the theoretical and empirical findings as well as analysis of the empirical findings.

In conclusion, further investigation of all BI software vendors is recommended with an in-depth analysis of CI cycle phases based on the enhanced evaluation criteria, as well as newly approached analysis and evaluation of recent BI developments, present market shares and pricing structures is suggested for further studies.

\section{References}

Aberdeen, G. (2008) The evolving face of BI. Retrieved from: www.btquarterly.com, on 2504-2009.

Amara Y. et al (2009) Evaluating Business Intelligence Software - Testing the SSAV Model, Thesis, Blekinge Institute of Technology, Sweden.

Bernhardt, D. “Tailoring Competitive Intelligence to Executives' Needs” Long Range Planning Vol. 27, Feb 1994, p. 18.

BI Editor (2008) SAS Acquires Teragram to Strengthen Text Mining and Analytics. Retrieved from: businessintelligencejournal.com, on 05-042009.

Bouthillier, F (2001) Comparative Analysis of CI Software, Graduate School of Information Studies, McGill University.

Briggs, L (2009). More Changes Ahead in BI Landscape. Retrieved from: tdwi.org, on 28-052009.

Burns, A. (2003) Business Intelligence: History \& The Intelligence Cycle, Australian Foresight Institute.

Cognos (2008) Industry Analyst Review. Retrieved from: www.cognos.com, on 2009-02-22.

Cognos (2008) The Full Promise of Business Intelligence. Retrieved from: www.cognos.com, on 2009-02-05.

Cognos (2004) Using BI to Leverage ERP Data. Retrieved from: www.cognos.com, on 2009-0205.

Cliff Mills (2008). BI for all. Retrieved from: www.evaluation.com, on 2009-02-07.

Chris Hall (2001). "The Intelligent Puzzle”. Competitive Intelligence Review, Vol. 12, 2001, pp 3-14.

Creswell, J.W. (2008) Educational Research: Planning, Conducting, and Evaluating Quantitative and Qualitative Research (3rd Edition), Merrill Prentice Hall, Upper Saddle, NJ.

Creswell, J.W. (1994) Research Design: Qualitative and Quantitative Approaches, Sage Publications, Thousand Oaks, CA.

Daems, J (2008) Independent BI vendors in a consolidated market: the case of MicroStrategy. Retrieved from: http://www.element61.be/e/resourcdetail.asp?ResourceId=58, on 28-05-2009. 
Desouza, K. "Intelligent Agents for Competitive Intelligence: Survey of Applications.” Competitive Intelligence Review, 2001, Vol. 12 (4), pp. 57-63.

Ericsson, Rob (2004) Building Business Intelligence Applications with NET, Charles River Media, Herndon, VA, USA.

Fleisher, G., Blenkhorn, D. (2001). An Introduction to the Management and Practice of CI: Managing Frontiers in Competitive Intelligence, Quorum Books, Westport.

Gartner Group (2009) Gartner Reveals Five Business Intelligence Predictions for 2009 and Beyond. Retrieved from: http://www.gartner.com/it/page.jsp?id=856714, on 29-05-2009.

Gartner, (2007. Business Intelligence Market Will Grow 10 Percent in EMEA in 2007. Retrieved from:

http://www.gartner.com/it/page.jsp?id=500, on 2009-02-22.

Gilad, B. "What is intelligence analysis?" Competitive Intelligence Magazine, 1998, 1(3), pp. 29-35.

Gilad, B \& Gilad, T., “A systems approach to business intelligence”, Business Horizons, 28(5), 1985, pp. 65-70.

Global Intelligence Alliance (2004) Introduction to Competitive Intelligence. Retrieved from: businessintelligence.com, on 05-26-2009.

Guntram Werther, Building an “Analysis Age for Competitive Intelligence in the Twenty-First Century”. Competitive Intelligence Review, 2001, Vol. 12 (1), pp. 41-47.

IBM Redbooks (2004) Preparing for DB2 NearReal-time Business Intelligence. Durham, NC, USA.

Jerry Brown (2008) Future of BI may not be BI. Retrieved from: www.evaluation.com, on 200902-07.

Johnson, A. (2000) Competitive Intelligence, Retrieved from: http://www.aurorawdc.com/whatisci.htm, on 2009-03-19.

Kelly, J. (2009) Business intelligence software market looks to hold its own during recession. Retrieved from: www. searchdatamanagement.techtarget.com, on 0517-2009.

Kelly, J (2009) Business intelligence software adoption lags BI vendors' perception. Retrieved from www.searchdatamanagement.com, on 2605-2009.

King, Rachel (2009) Business intelligence's software time is now. Retrieved from: http://www.businessweek.com/technology/cont ent/mar2009/tc2009032_101762.htm, on 25-042009.

Larson, Brian (2006) Delivering Business Intelligence with Microsoft SQL Server 2005, McGraw-Hill Osborne Media.

Martell, J. (2009) Difference between Business Intelligence (BI) and Competitive Intelligence (CI) Software. Retrieved from: competitiveintelligence.com, on 05-06-2009.

Michael C.O`Guin, Timothy Ogilvie, “The Science, Not Art, of Business Intelligence”, Competitive Intelligence Review, 2001, Vol. 12 (4), pp. 15-24.

Power, D. J. (2007) A Brief History of Decision Support Systems. Retrieved from: http://dssresources.com/history/dsshistory.html, on 2009-02-20.

PCMAG, BI Software. Retrieved from: http://www.pcmag.com/encyclopedia_term/0,25 $42, \mathrm{t}=\mathrm{BI}+$ software\& $\mathrm{i}=38583,00$.asp, on $05-29$ 2009.

Prescott, John E. (2001) Proven Strategies in Competitive Intelligence: Lessons from the Trenches, John Wiley \& Sons, New York.

Reality Software (2009) Business Intelligence Software Development. Retrieved from: http://www.realitysoftware.ca/services/software -development/business-intelligence/, on 200902-14.

SAP (2008) All Information, All People, One Platform: What's New In SAP Business Objects $X I$ 3.1. Retrieved from www.sap.com/sapbusinessobjects, on 2009-0206.

SAS Institute Inc. (2008) The SAS Enterprise Intelligence Platform: SAS Business Intelligence. Retrieved from: www.sas.com, on 2009-02-05.

SAS Institute Inc. (2007) Business Intelligence Maturity and the Quest for Better Performance. Retrieved from www.sas.com, on 2009-02-05.

Solberg Søilen K., Amara, Y, Vriens, D. (2008) Evaluating Business Intelligence Software Testing the SSAV Model, Working paper, Blekinge Institute of Technology, Sweden. Suppiah, S (2009) Vendors in Gartner's BI Magic Quadrant 2009. Retrieved from 
http://www.networkworld.com/news/2009/0129 09-vendors-in-gartners-bi-magic.html, on 0520-2009.

Thierauf, Robert J. (2001) Effective Business Intelligence Systems, Quorum Books, Westport, USA.

The Chartered Institute of Management Accountants (2008) Improving decision making in organizations: Unlocking Business
Intelligence. Retrieved from www.cimaglobal.com, on 2009-02-17. Van Grembergen, Wim (2001) Information Technology Evaluation Methods and Management, Idea Group Publishing, Hershey, PA, USA.

Vriens, Dirk Jaap (2003) Information and Communications Technology for Competitive Intelligence, Idea Group Inc, Hershey, PA, USA. 